\title{
Animal Pre-Surgical Unilateral Nasal Stent for Bite Case
}

\section{Manu Rathee*}

Pandit Bhagwat Dayal Sharma University of Health Sciences, Haryana, India

\begin{abstract}
Nasal stent accomplishes multiple roles in rhinoplasty cases. Placement of nasal stent both pre-and post-surgical rhinoplasty is aimed at maintaining airway, tissue position and reduces tissue contracture during healing period. This article provides a simplified technique of nasal stent fabrication prior to surgical rhinoplasty in case of dog bite with an immediate approach.
\end{abstract}

Keywords: Nasal deformity; Nasal stent; Rhinoplasty

\section{Introduction}

Face is the most noticeable of human characteristics and arguably the nose is its most prominent feature. Deformities of nose can occur as a result of a congenital absence or defect, traumatic avulsion or disfigurement and surgical excision or contracture after tumour resection $[1,2]$. Surgical and/or prosthetic procedures using intranasal prostheses or stents have been developed to improve both form and function. Subtotal removal of nasal structures often leaves mobile tissue, which is difficult to use for support or retention of a nasal prosthesis. Intranasal prostheses can support mobile tissue and provide reinforced edges that more readily accept a retentive interface. They maintain patent nasal airways and provide mechanical retention for securing nasal prostheses. Stent (after Charles R. Stent) defined as a mold for supporting a soft tissue or bony graft during healing. It can also be defined as "an appliance that maintains the tissues in a predetermined position". Provision of intranasal prosthesis aids in maintenance of airways after graft procedure, minimize cicatricial contraction, and counteract previously formed scar tissue, maintenance of a patent nasal airway in case of deviated nasal septum [3-5].

Other uses of intranasal stents in reconstructive surgery are temporary stents around which split-thickness skin grafts can be placed, providing support for cartilage transplants, stents for use after surgery on cleft lip deformities. The need for an internal support mechanism may be accomplish with a nasal stent, fabricated to act as an internal scaffold to support the graft and residual tissues. A codependency of osteocartilaginous framework along with viable tissue requires time to heal to maintain form and structure of the nose. Such codependency that exists between the framework and lining makes surgical reconstruction to achieve function difficult. Hence, the need for an internal support mechanism may be accomplish with a nasal stent $[6,7]$.

\section{Case Report}

A 12-year-old female patient was referred to the Department of Prosthodontics and Crown \& Bridge, Post Graduate Institute of Dental Sciences, Rohtak for the fabrication of nasal stent, to maintain post reconstructive position of corrected nasal cartilage, by the Department of Surgery of Post Graduate Institute of Medical Sciences, Rohtak. There was history of dog bite 2 days back for which emergency treatment was provided including the medications (Figure 1).

\section{Clinical Procedure}

For intranasal impression, the patient was made to sit upright in the dental chair to prevent distortion of the soft tissues. Petroleum jelly was applied to facilitate the easy removal of the impression. The impression compound was then softened, molded into a cylindrical core with U-shaped form across the columela and inserted into each nasal vestibule of the patient and was molded to achieve the approximate length of the nasal cavity (Figure 2). An impression of the external nasal region was made with irreversible hydrocolloid and backing of impression compound (Figures 3 and 4). Intranasal pin-hole stent was fabricated using clear acrylic resin following conventional investing and processing procedure (Figure 5). It was finished and polished. The internal surface of the stent was highly polished to reduce mucus adhesion to the surface. The prosthesis was inserted into the nasal vestibule and the patient was instructed to wear it till healing was complete and surgery was planned (Figure 6). Involvement of the unaffected left nostril was to provide the retention to the prosthesis. Patient was instructed for continuous wearing and hygiene maintenance. Frequent post-insertion appointments were scheduled and normal recovery was observed during follow up.

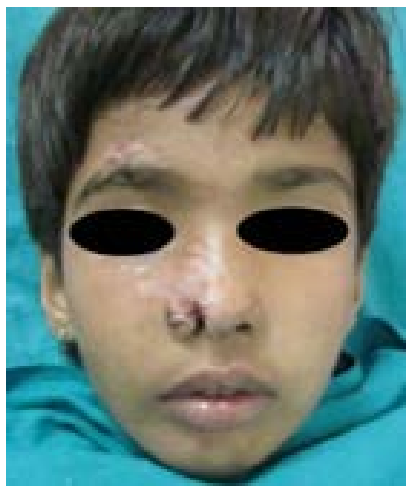

Figure 1: Pre-operative frontal view.

*Corresponding author: Manu Rathee, Pandit Bhagwat Dayal Sharma University of Health Sciences India, Rohtak, Haryana, PIN 124001, India, Tel: 91-1262-211300-03; E-mail: ratheemanu@gmail.com

Received September 14, 2014; Accepted November 22, 2014; Published November 24, 2014

Citation: Rathee M. (2014) Animal Pre-Surgical Unilateral Nasal Stent for Bite Case. J Trauma Treat 4: 223. doi:10.4172/2167-1222.1000223

Copyright: (C) 2014 Rathee M. This is an open-access article distributed under the terms of the Creative Commons Attribution License, which permits unrestricted use, distribution, and reproduction in any medium, provided the original author and source are credited. 


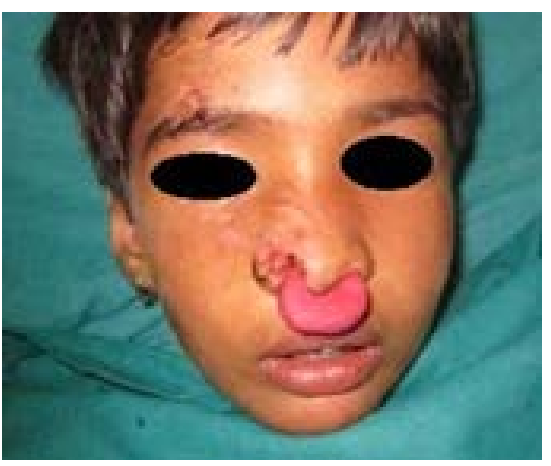

Figure 2: Intranasal impression with impression compound.

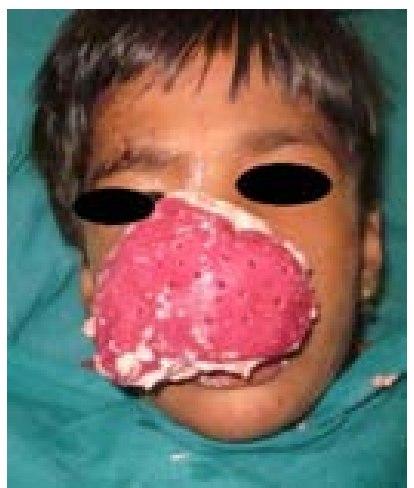

Figure 3: Extranasal impression with irreversible hydrocolloid

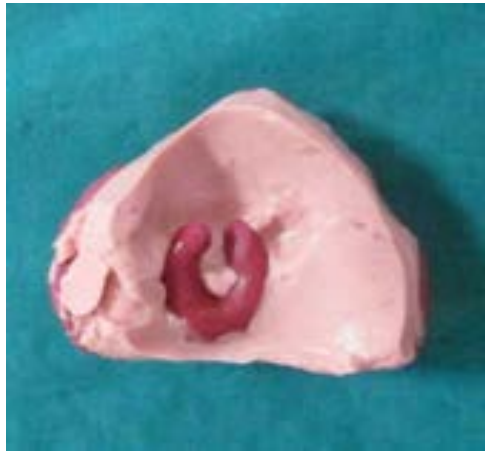

Figure 4: Completed impression.

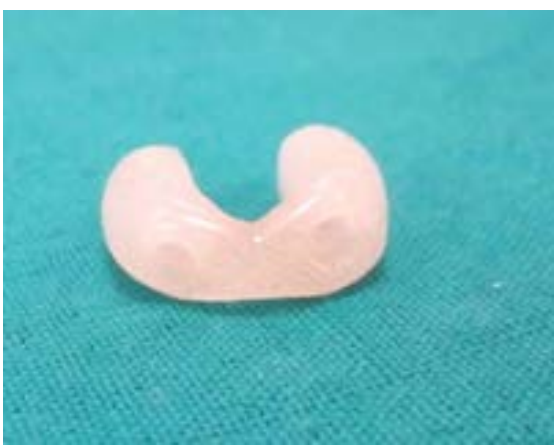

Figure 5: Finished and polished nasal stent

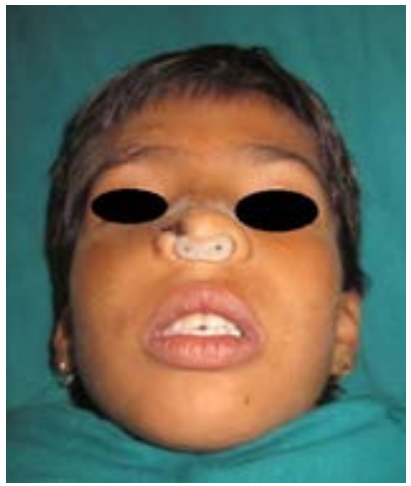

Figure 6: Nasal stent in situ.

\section{Conclusion}

The splints and stents are excellent examples of preventive prosthodontic devices in the field of maxillofacial prosthetics. Although many different techniques are there for managing common problems, the choice mainly depends on patient's condition and operator's choice as every patient presents a unique clinical situation.

\section{References}

1. Beumer J III, Curtis TA, Marunick MT (1996). Maxillofacial rehabilitation prosthodontic and surgical considerations. St Louis: Ishiyaku EuroAmerica; p. 455-477.

2. Parel SM (1980) Intranasal conformers. J Prosthet Dent 43: 439-444.

3. [No authors listed] (2005) The glossary of prosthodontic terms. J Prosthet Dent 94: 10-92.

4. Seals RR Jr, Bohnenkamp LG, Parel SM (1988) Intranasal prostheses, splints, and stents. J Prosthet Dent 60: 595-601.

5. Young JM (1970) Internal nares prosthesis. J Prosthet Dent 24: 320-323.

6. Naveen S, Viswambaran M (2013). Intranasal Prosthesis to Maintain ThreeDimensional Stability of the Nose after Surgical Reconstruction- Case Report Int J Sci Res; 2(12): 470-471.

7. Nagaraj E, Shetty N, Mankani N, Subramanian M. Rao, Gurram S M (2012) Nasal Stent Fabrication for an Atrophic Rhinitis Patient: A Simplified Technique. JCDR 6(3):530-532. 